\title{
Konsep Pemikiran Pendidikan Toleransi Fethullah Gulen
}

\author{
Muhammad Anas Ma'arif ${ }^{1}$, \\ ${ }^{1}$ Mahasiswa Pascasarjana UIN Maliki Malang \\ ${ }^{1}$ email.anasdt16@gmail.com
}

\begin{abstract}
The purpose of writing this article is to explain the concepts, thoughts and application of education according to Gulen. Such as the integration of Islam and science, the internalization of love and tolerance, modern tasawuf, the golden generation, Islam rahmatan lil alamin and human services with hizmet. This paper uses the library research method by collecting books, journal articles, original web and writings that are relevant to the themes discussed. Finding: Fethullah Gulen is an influential figure in the world of education as evidenced by schools managed by Gulen Movement established in 130 countries. Gulen applies hizmet as a missionary service to serve people who are engaged in the world of education. Modern sufist education models that integrate esoteric aspects and exoteric aspects. Teaches love in education, tolerance by dialogue and integrating Islam and science as a whole. All of them are to form a golden generation that is able to answer the changing times and become a man of love and a harmonious life.
\end{abstract}

Key Word: Tolerance, Education Concept, Fethullah Gulen,

\begin{abstract}
Abstrak
Tujuan dari penulisan artikel ini adalah untuk menjelaskan konsep, pemikiran dan penerapan pendidikan menurut Gulen. Seperti integrasi Islam dan sains, internalisasi cinta dan toleransi, tasawuf modern, generasi emas, Islam rahmatan lil alamin dan pelayanan manusia dengan hizmet. Tulisan ini menggunakan metode penelitian kepustakaan dengan mengumpulkan buku, artikel jurnal, web asli dan tulisan-tulisan yang relevan dengan tema yang dibahas. Temuan: Fethullah Gulen merupakan tokoh yang berpengaruh dalam dunia pendidikan dibuktikan dengan sekolah yang dikelola oleh Gulen Movement berdiri di 130 Negara. Gulen menerapkan hizmet sebagai dakwah untuk melayani masyarakat yang bergerak pada dunia pendidikan. Model pendidikan sufistik modern yang mengintegrasikan aspek esoteris dan aspek eksoteris. Mengajarkan cinta dalam pendidikan, toleransi dengan berdialog dan mengintegrasikan Islam dan sains secara utuh. Kesemuanya untuk membentuk generasi emas yang mampu menjawab perubahan zaman dan menjadi menusia yang cinta dan kehidupan yang harmonis.
\end{abstract}

Kata Kunci: Toleransi, Konsep Pendidikan, Fethullah Gulen

\section{Pendahuluan}

Fathullah Gulen adalah cendikiawan muslim yang berasal dari Turki dan paling berpengaruh di dunia ${ }^{1}$. Gulen menarik jutaan pengikutnya yang telah mendirikan lembaga pendidikan dan budaya di seluruh dunia. Hal ini terbukti bahwa sekolah dengan model yang ditawarkan oleh Gulen beridiri di 130 Negara hingga saat ini dimungkinkan lebih. Dari beberapa negara tersebut terdapat 1000 afiliasi lembaga sekolah². Filosofi yang diajarkan oleh Gulen adalah menggabungkan Islam dengan modernitas, toleransi dengan

\footnotetext{
1 Salih Yucel, "Fethullah Gulen: Spiritual Leader in a Global Islamic Context," 2010, 1, https://dspace2.creighton.edu/xmlui/handle/10504/64593.

${ }^{2}$ Mubaidi Sulaiman, "Konsep Pendidikan Islam dalam Perspektif Muhammad Fethulah Gulen,” Didaktika Religia 4, no. 2 (2016): 64.
}

Tribakti: Jurnal Pemikiran Keislaman

Volume 30, Nomor 2, Juli 2019 
berdialog, humanisme dan pendidikan toleransi berbasis cinta ${ }^{3}$. Keunikan dari ajaran Gulen adalah memadukan antara Islam dan sains dengan ilmiah, tasawuf dengan modernitas, akal dan hati rasio dan wahyu serta intelektual dan spiritual ${ }^{4}$.

Gerakan Fethullah Gulen atau juga disebut Gulen Movement (GM) adalah gerakan yang dilandasi oleh cinta, iman dan sunnah Nabi. GM lebih memprioritaskan pelayanan manusia (hizmet) ${ }^{5}$ melalui pendidikan dan filantropi ${ }^{6}$, toleransi beragama dan toleransi sosial dengan dialog, menjadikan Islam sebagai rahmatan lilalamin ${ }^{7}$. Gulen percaya bahwa untuk melahirkan generasi emas dan manusia-manusia yang kamil adalah dengan pendidikan. Pendidikan bertujuan untuk menjadikan manusia yang berbudi luhur, memerangi kebodohan, memerangi kemiskinan dan menghilangkan perpecahan kelompok. Pendidikan adalah cara terbaik untuk hizmet kepada manusia dan membangun peradaban manusia yang tinggi dengan dialog ${ }^{8}$.

Karakteristik pendidikan yang terdapat dalam sekolah-sekolah Gulen dalah dengan konsep sufistik yang mengakomodir modernisasi. Gulen mengajarkan transmisi nilai-nilai spiritual, moral berprilaku, toleransi, rasa hormat keterbukaan dan sejenisnya. Melalui transformasi spiritual individu yang terinternalisasi akan datang transformasi sosial yang lebih luas dan setidaknya dalam masyarakat Islam akan terbentuk harmonis yang utuh ${ }^{9}$. Gulen memasukan kurikulum dalam pendidikannya dengan ilmu pengetahuan (sains) dan pengetahuan iman (esoteris) agar lulusanya menjadi manusia ideal $^{10}$.

Di samping pendidikan yang digaungkan oleg GM dan pengikutnya, Gulen juga mengajarkan cara hidup berdampingan yang harmonis melalui dialog ${ }^{11}$. Dialog agar menumbuhkan toleransi terhadap manusia satu sama lain karena Gulen sendiri berpendapat bahwa Islam adalah agama yang indah dan harmonis. Intoleransi diakibatkan oleh ketidak-pahaman seorang dalam memahami Islam secara penuh. Pemaknaan ayatayat jihad yang kurang tepat sehingga ia merasakan bahwa Islam seperti kekerasan ${ }^{12}$.

Pemikiran dan tindakan Gulen mendapatkan sambutan dan apresiasi dari berbagai lapisan masyarakat dengan lintas budaya, etnis, suku dan bangsa. Pengikut Gulen menamakan dirinya dengan Gulenisme atau Fethullah Gulen Movement. Gerakan yang digawangi oleh Gulen ini menawarkan sejumlah jalan hidup berupa Islam yang rahmatan lil alamiin, Islam yang ramah di tengah-tengah ancaman isu radikalisme, terorisme dan fundamentalisme. Hingga saat ini gerakan Gulenisme menyebar di berbagai penjuru

\footnotetext{
${ }^{3}$ Ahmad Rizqon Khamami, "Dialog antariman dalam Perspektif Fethullah Gülen," Religio: Jurnal Studi Agama-Agama 2 , no. 1 (2012): 8 .

${ }^{4}$ Khamami, 8-9.

${ }^{5}$ Mucahit Bilici, “The Fethullah Gulen Movement and Its Politics of Representation in Turkey*," The Muslim World 96, no. 1 (Januari 2006): 4, https://doi.org/10.1111/j.1478-1913.2006.00115.x.

${ }^{6}$ Gulen Fethullah, "Educational services are spreading throughout the world - Fethullah Gülen's Official Web Site," diakses 28 Mei 2019, https://fgulen.com/en/fethullah-gulens-works/toward-a-global-civilization-of-love-and-tolerance/education/25270educational-services-are-spreading-throughout-the-world.

${ }^{7}$ Mua'mmar M Arfan dan Hasan Abdul Wahid, Studi Islam Perspektif Insider dan Outsider, 2 ed. (Yogyakarta: IRCiSoD Anggota Ikapi, 2013), 517.

${ }^{8}$ Fethullah, "Educational services are spreading throughout the world - Fethullah Gülen's Official Web Site."

${ }^{9}$ Bill Park, "The Fethullah Gülen Movement as A," t.t., 14.

${ }^{10}$ Mutamakkin Billa, "Pemaknaan Teologis M. Fethullah Gülen tentang Relasi Agama dan Sains," Teosofi: Jurnal Tasawuf Dan Pemikiran Islam 1, no. 2 (1 Desember 2011): 292, https://doi.org/10.15642/teosofi.2011.1.2.290-316.

${ }^{11}$ Muzalevsky Roman, "Fethullah Gulen's Movement in Central Asia: A Blessing or a Curse?," diakses 28 Mei 2019 , http://www.cacianalyst.org/publications/analytical-articles/item/11895-analytical-articles-caci-analyst-2009-9-1-art-11895.html. 160 .

${ }^{12}$ Hulaimi Al Amin, "Pandangan Fethullah Gulen Tentang Toleransi Beragama," Al-Majaalis 4, no. 1 (20 November 2016):
} 
dunia melalui kegiatan filantopi, aktivitas budaya, kegiatan pendidikan, dialog dan gerakan sosial ${ }^{13}$.

Dari beberapa pemaparan diatas penulis mencoba untuk memahani dan menganalisis konsep dan praktik pendidikan Gulen. Seperti bagiamana pendidikan sufistik modern? Bagimanakah pendidikan Islam dan sains? dan bagaimanakah penerapan toleransi dengan dialog? Oleh sebab itu, semoga tulisan ini berkontribusi terhadap perkembangan pendidikan saat ini serta relevansinya terhadap perkembangan zaman.

\section{Pembahasan \\ Biografi Fethullah Gulen}

Gulen kecil lahir di Negera Turki di daerah Korocuk pada tanggal 11 November 1938. Gulen dilahirkan oleh keluarga harmonis yang sangat agamis dengan semangat keIslaman yang membumi. Kakeknya adalah seorang yang teguh dan sungguh-sungguh mengamalkan ajaran Islam sehingga sosok inilah yang memiliki ikatan kuat dengan Gulen, (cucunya). Gulen kecil yang sejak dini diajari oleh ibunya mengaji dan rutin membaca Al-Qur an hingga pada usia empat tahun, ia sudah sanggup menghatamkan AlQur`an dalam kurun waktu satu bulan. Gulen mewarisi kecintaanya kepada Nabi SAW dari ayahnya yang selalu membaca kisah-kisan Nabi SAW. Ramiz Gulen ayah dari Fethullah Gulen menanamkan sejak dini kecintaan kepada Nabi SAW sehingga membentuk kepribaian Gulen yang mencintai Nabi SAW ${ }^{14}$.

Pendidikanya dimulai dari keluarganya sendiri dan kemudian dilanjutkan ke pendidikan lembaga resmi di kota Erzurum Turki ${ }^{15}$. Sementara itu, pendidikan spiritual yang dipelajari oleh Gulen diawali dari ayahnya sendiri dan kemudian berguru kepada M. Lutfi Efendi ${ }^{16}$. Hal inilah yang menjadikan titik awal bahwa Gulen akan membentuk kepribadianya dengan spiritual sufistik yang modern. Gulen mempelajari ilmu-ilmu keagaman dengan seksama dan cermat dari ulama Osman Bektasi. Bahkan Gulen juga secara otodidak mempelajari ilmu-ilmu sains seperti biologi, fisika, kimia dan sebagainya ${ }^{17}$.

Walaupun tidak pernah bertemu dengan Badiuzzaman Said Nursi, tetapi Gulen sangat mengidolakanya. Ia belajar dari murid-muridnya Said Nursi untuk melanjutkan perjuanganya yaitu bervisi moderat, komprehensif dan modern. Gerakan pembaharuan Said Nursi yang diteruskan Gulen adalah pembaharuan yang mencakup seluruh aspek kehidupan ${ }^{18}$. Gulen tumbuh dewasa dengan semangatnya mampu menulis karya-karya hingga hampir 70 buku dan rekaman-rekamanya juga hampir 1000 kaset yang sudah

\footnotetext{
${ }^{13}$ Helen Rose Fuchs Ebaugh, The Gülen movement: a sociological analysis of a civic movement rooted in moderate Islam (Dordrecht [the Netherlands] ; London ; New York: Springer, 2010), 13.

14 Gulen Fethullah, "Siapakah Fethullah Gülen? - Fethullah Gülen Situs Web," diakses 30 Mei 2019, https://fgulen.com/id/profil/biografi-fethullah-gulen/35531-siapakah-fethullah-gulen.

${ }^{15}$ Gulen Fethullah, "Pendidikan Dasar dan Kepribadian M. Fethullah Gülen - Fethullah Gülen Situs Web," diakses 30 Mei 2019, https://fgulen.com/id/profil/biografi-fethullah-gulen/33351-pendidikan-dasar-dan-kepribadian-m-fethullah-gulen.

${ }^{16}$ M Arfan dan Abdul Wahid, Studi Islam, 504.

17 Gulen Fethullah, "Biografi Singkat Fethullah Gülen - Fethullah Gülen Situs Web," diakses 30 Mei 2019, https://fgulen.com/id/profil/biografi-fethullah-gulen/34168-biografi-singkat-fethullah-gulen.

${ }_{18}$ Tugrul Keskin, "A Comparative Analysis of Islamist Movements in the Neoliberalization Process: Jamaâ at-e- Islami in Pakistan and the Fethullah Gulen Movement in Turkey â Reactions to Capitalism, Modernity and Secularism," 9 September 2009, 15, https://vtechworks.lib.vt.edu/handle/10919/29681.
}

Tribakti: Jurnal Pemikiran Keislaman

Volume 30, Nomor 2, Juli 2019 
dipublikasikan. Semangatnya dalam membangun manusia seutuhnya lewat pendidikan diaktualisasikan dalam hizmet. Pelayanan pendidikan ia bentuk untuk melayani masyarakat. Gulen juga pernah masuk dalam majalah 100 tokoh berpengaruh dan penting di dunia.

\section{Pendidikan Sufistik Modern}

Gulen mengaktualisasikan pemikiranya dalam pendidikan berupa hizmet. Ia menganggap bahwa membentuk manusia yang beradab dapat diperoleh lebih dari aspek pendidikan. Pendidikan adalah cara yang tepat untuk memberikan pelayanan kepada masyarakat dan membangun peradaban manusia. Memberikan pendidikan dengan tepat kepada orang lain dengan aktif melakukan pengabdian kepada masyarakat yang berbarti bahwa kegiatan hizmet bertujuan untuk membangun dan mengembangkan individu yang bermoral, berakhlak mulia, beretika dan mampu membawa manusia kepada kebahagiaan dunia dan akhirat. Oleh sebab itu, sekolah adalah tempat untuk membentuk karakter seseorang setelah pendidikan keluarga ${ }^{19}$.

Pelayanan pendidikan yang dilakukan oleh Gulen Movement adalah dengan mendidik seorang dengan utuh dan komprehensif, baik secara akal atau secara rohani. Hal ini diakomodir keduanya, artinya Gulen menginginkan manusia menguasai dan memahami realitasnya sebagai makhluk Allah yang sempurna. Penerapan pemikiran Gulen tidak terlepas dari pengalamannya dalam mengenyam pendidikan ${ }^{20}$. Gulen dibentuk menjadi agamis karena pengaruh dari ayahnya dan guru-gurunya. Pemikiran Gulen tentang dunia sufistik yang modern terpengaruh dari buku "Risala-i an Nur" karya Said Nursy. Sehingga dalam penerapan pendidikanya ia mengajar siswa-siswanya untuk berkumpul dalam seminggu sekali dan belajar kitab karya Siad Nursy tersebut ${ }^{21}$.

Pendidikan yang diterapkanya adalah dengan mengintegrasikan esoteris dan eksoteris. Keduanya dinilai mampu membawa manusia menuju pluralitasnya. Dimensi esoteris dan esoterik dalam Islam tidak bisa dipisahkan satu sama lain karena keduanya bagai sisi mata uang ${ }^{22}$. Esoteris juga disebut pendidikan untuk membentuk hati atau juga disebut tazkiyah an-nafs. Sedangkan dimensi eksoteris adalah pendidikan sains. Sehingga muara akhir dari pendidikan ini adalah cinta dan harmonisme manusia ${ }^{23}$.

Pemikiran Gulen tentang pendidikan sufistik adalah spirit mendasar yang menjadi landasar dari semua konsep-konsep pemikirannya. Gulen menekankan pada tazkiyah nafs, pengabdian diri kepada masyarakat (hizmet), taubat, taqwa, zuhud, ikhlas, istikamah, muraqabah, tawadhu', ihsan, syukur, sabar dan makrifat ${ }^{24}$. Konsep sufistik merupakan ekspresi dari usaha pencerahan pembentukan generasi emas yang mampu mengamalkan iman, cinta kasih, dan meneladani Nabi SAW dalam kehidupannya. Sedangkan wujud langsung dari penerapan konsep-konsep tersebut adalah dengan

\footnotetext{
${ }^{19}$ Sulaiman, "Konsep Pendidikan Islam dalam Perspektif Muhammad Fethulah Gulen," 75.

${ }^{20}$ D. I. Ansusa Putra, "Epistemologi Tafsir Sufi Perspektif Esoterik-Fenomenologi," Ulul Albab Jurnal Studi Islam 19, no. 2 (28 Desember 2018): 193, https://doi.org/10.18860/ua.v19i2.5019.

${ }^{21}$ Akhmad Rizqon Khamami, "Paradigma Dakwah Islam Fethullah Gulen Di Abad Kontemporer," Islamica: Jurnal Studi Keislaman 12, no. 2 (29 November 2018): 372, https://doi.org/10.15642/islamica.2018.12.2.358-383.

${ }^{22}$ M Arfan dan Abdul Wahid, Studi Islam, 474.

${ }^{23}$ Charles Nelson, "Fethullah Gülen: A Vision of Transcendent Education," t.t., 13.

${ }^{24}$ Hadi Purnomo dan Umiarso Umiarso, "Pengelolaan Dan Sistem Pendidikan Islam Berwawasan Rahmatan Lil'alamin: Kajian Atas Gerakan Pendidikan Fethullah Gulen Movement," Cendekia: Jurnal Kependidikan Dan Kemasyarakatan 16, no. 2 (22 November 2018): 87, https://doi.org/10.21154/cendekia.v16i2.1288.
} 
pelayanan kepada masyarakat (hizmet), dakwah dengan dialog toleransi, mengutamakan uswah dan keteladanan dari pada sekedar menyuruh ${ }^{25}$. Pemikiran konsep pendidikan sufistik ini dapat ditemukan dari beberapa karyanya yang telah ia tulis.

Berdasarkan karya-karya Gulen maka dapat dijadikan karakteristik pendidikan sufistik sebagai berikut:

1. Golden Generation/Generasi Emas

Generasi emas adalah seorang yang mampu mengamalkan nilai-nilai agama secara komprehensif dan mengaktualisasikan dirinya sebagai manusia yang sempurna ${ }^{26}$. Generasi yang akan dibentuk oleh Gulen adalah seorang yang menjalankan segala perbuatannya dengan $\operatorname{cinta}^{27}$. Visi akhir dari konsep pendidikan Gulen adalah untuk membentuk "Generasi Emas," generasi manusia universal yang ideal, manusia yang mencintai kebenaran, yang mengintegrasikan spiritualitas dan pengetahuan, yang bekerja untuk memberi manfaat bagi masyarakat. Seperti pemaparan berikut:

"The end of Gülen's educational vision is to raise a "Golden Generation," a generation of ideal universal individuals, individuals who love truth, who integrate spirituality and knowledge, who work to benefit society". 28

Menurut Gulen karakteristik generasi emas seperti Iskandar Zurkarnain yang memiliki dua sayap. Dua sayap dijelaskan seperti seorang yang mampu mengintergrasikan secara seimbang akal/pikiran dan hati. Penggabungan nilai-nilai universal antara sains dengan pengetahuan modern yang menghasilkan orang-orang yang tulus dan jujur dan tercerahkan. Melakukan pelayanan kependidikan dan sosial secara cinta dan kasih sayang ${ }^{29}$. Hal ini dibuktikan Gulen dalam tiga lembaga yaitu: 1) Universitas Fatih: mendiskusikan pemikran Gulen secara formal dan informal. 2) Asrama (Dormitories), untuk mempersiapkan siswa masuk universitas. 3) Gulen Inspired School untuk model pendidikan transnasional ${ }^{30}$.

Golden generation ini tidak akan mudah dicapai. Pencapainya haruslah bisa mengakomodir pendidikan spiritual dengan kecerdasan otak. Hal ini juga bisa disebut sebagai integrasi Islam dan sains secara utuh. Menyeimbangkan pendidikan model ini harus terdapat komitmen penuh dari lembaga pendidik dan semua warga sekolah. Akan tetapi Gulen mencoba untuk menepis pendapat bahwa pendidikan model integrasi ruhanian dan jasmaniah susah didapatkan. Ia mengimplementasikan visi, misi dan tujuan yang terkonsep dalam pemikirannya dengan melakukan pelayanan pendidikan kepada masyarakat.

${ }^{25}$ Sokhi Huda, "Pemikiran Dan Praksis Dakwah Sufistik M. Fethullah Gülen," ISLAMICA: Jurnal Studi Keislaman 11, no. 2 (13 Maret 2017): 313, https://doi.org/10.15642/islamica.2017.11.2.311-338; Anang Haderi, “Takdir Dan Kebebasan Menurut Fethullah Gülen,” Jurnal Theologia 25, no. 2 (2014): 49-80, https://doi.org/10.21580/teo.2014.25.2.381.

${ }^{26}$ Nelson, "Fethullah Gülen: A Vision of Transcendent Education."

${ }^{27}$ Gürkan Çelik, The Gülen movement: building social cohesion through dialogue and education (Delft: Eburon, 2010$), 98$.

${ }^{28}$ Fethullah Gülen, Towards the lost paradise, 2nd ed (Konak, İzmir: Kaynak, 1998).

${ }^{29}$ Fethullah Gülen, Pearls of wisdom (Fairfax, Va: The Fountain, 2000), 20.

${ }^{30}$ Purnomo dan Umiarso, "Pengelolaan Dan Sistem Pendidikan Islam Berwawasan Rahmatan Lil'alamin," 87. 
Tujuan yang telah dipaparkan di atas sama seperti tujuan dari pendidikan sufistik yaitu membentuk manusia yang utuh atau juga disebut dengan insan kamil ${ }^{31}$. Manusia yang mampu mengamalkan nilai-nilai agama secara penuh dan menjadi khalifah fil ardh. Seorang sufi sejati adalah mampu mengintegrasikan zikir dan fikir secara optimal sehingga seorang tersebut mampu mengetahui jati dirinya sendiri ${ }^{32}$.

Gulen memberikan standar nilai dasar pendidikan dalam membentuk manusia unggul atau golden generation sebagai berikut ${ }^{33}$ :

a. Moralitas dan trandar visi misi akademik yang tinggi.

b. Pembentukan karakter seperti: cinta, toleransi dan doalog sebagai sarana utama.

c. Pembelajaran ditujukan pada cinta dan toleransi sesama manusia, moralitas keagamaan dan membangun karakter.

d. Guru menjadi suri tauladan yang baik dengan mentransformasikan nilai karakter.

e. Tujuan pendidikan adalah terciptanya perilaku positif.

f. Terbentuknya rekonsiliasi antara pemikiran dan hati (marriage of mind and heart)

g. Nilai-nilai yang harus diinternalisasikan di sekolah Gulen: kejujuran, multikulturalisme, kerja keras, cinta, toleransi, harmoni dan dialog.

2. Cinta dan Toleransi/Love and Tolerance

Gulen mengajarkan kepada murid-muridnya agar dalam melakukan hizmet dilandasi dengan cinta dan respect. Cinta adalah dasar dari pendidikan ${ }^{34}$. Muara akhir dari pendidikan yang dikonsep Gulen adalah cinta ${ }^{35}$. Gulen juga mengaktualisasikan dalam bentuk cinta kasih, cinta sesama, saling menghargai dan toleransi.

Cinta adalah elemen penting dalam diri seorang. Cinta juga merupakan esensi dari seleruh ekspresi manusia ${ }^{36}$. Dengan cinta seorang akan melakukan pengorbanan dengan memulai tindakan patuh kepada Tuhan Yang Maha Esa. Dengan cinta seorang akan peduli terhadap sesama melakukan hal-hal dengan tanpa pamrih dan melakukan perbaikan pribadi untuk mengubah kehidupan di bumi. Menurut Gulen bahwa kekerasan dan kerusakan di dunia ini karena tidak adanya cinta dalam diri manusia tersebut.

Menurut Gulen, jalan yang ditempuh untuk membentuk cinta dan toleransi adalah melalui pendidikan. Dalam pendidikan dilakukan prinsip-prinsip agar tercapai tujuan pendidikan yaitu cinta kasih. Gulen mengajarkan para pemuda dari seluruh elemen masyarakat dan seluruh sektor kehidupan untuk menjadi profesional dan

\footnotetext{
${ }^{31}$ H. Cecep Alba, Tasawuf dan Tarekat: Dimensi Esoteris Ajaran Islam, Cet. 1 (Bandung: Anggota Ikapi, 2012 ), 18.

${ }^{32}$ Baharuddin, Paradigma Psikologi Islami, Studi tentang Elemen Psikologi dari Al-Qur'an, 2 ed. (Yogyakarta: Pustaka Pelajar, 2007), 301.

${ }^{33}$ Hairul Imam, "Perspektif M. Fethullah Gulen tentang Golden Generation dan Relevansinya dengan Pendidikan Islam di Indonesia," Marâji : Jurnal Ilmu Keislaman 2, no. 2 (1 Maret 2016): 267.

${ }^{34}$ Nelson, "Fethullah Gülen: A Vision of Transcendent Education," 6.

${ }^{35}$ Asma Afsaruddin, "The philosophy of Islamic education: Classical views and M. Fethullah Gulen's perspectives," dalam laman http://fethullahgulenconference. org/houston/read. php, 2005, 20.

${ }^{36}$ William C Chittick, Jalan Cinta Sang Sufi, Ajaran-Ajaran Spiritual Jalaluddin Rumi, trans. oleh Ismail M Sadat dan Nidjam Achmad, 2 ed. (Yogyakarta: Qalam, 2000), 195-96.
} 
terlatih. Kemudian para alumni akan mengajakan sebaliknya dengan cinta yang telah diperolehnya ${ }^{37}$.

Gulen mengajarkan cinta kepada muridnya karena tersinpirasi dari Nabi Muhammad SAW dan Jalaluddin Rumi. Nabi Muhammad adalah manusia yang penuh cinta dan kasih sayang (pride of humanity). Dijelaskan dalam salah satu nama Nabi Saw adalah Habibullah yang bermakna mencintai Allah dan dicintai Allah. Sedangkan cinta Gulen yang terinspirasi Jalaludin Rumi adalah dengan mengutip beberapa puisinya dan menulis beberapa buku sufisme ${ }^{38}$. Gulen juga menjelaskan bahwa menurut Rumi esensi dari semua amal yang dilakukan adalah cinta yang mendalam. Cinta yang kuat teraktualisasi dari keyakinan dan tebalnya iman seorang ${ }^{39}$.

Cinta dan toleransi diintegrasikan Gulen kedalam kurikulum pendidikanya ${ }^{40}$. Untuk menyokong kurikulum dan konsep pendidikannya Gulen membentuk jaringan pendidikan yang memuat sekolah, keluarga, masyarakat, organisasi kultural, organisasi agama dan tempat kerja yang kondusif. Sistem pendidikan tersebut yang dibentuk Gulen dilandasi dengan keterbukaan dan pelayanan kepada masyarakat sehingga aktualisasi cinta dan toleransi semakin terlaksana.

3. Islam rahmatan lil alamin. Demokrasi dan Moderat

Islam dipandang oleh sekelompok orang dengan kolot, fundamental dan teroris. Hal ini ditepis oleh Gulen bahwa Islam adalah agama yang demikian. Gulen menyerukan bahwa orang yang tidak mengenal Islam dengan baik, memahami ayatayat jihad dengan benar, maka orang tersebut tergolong eksklusif dan bisa jadi intoleran. Gulen adalah termasuk orang pertama yang mengecam tentang tragedi 11 September di Amerika Serikat karena wajah Islam sesungguhnya bukan seperti itu. Islam adalah damai, rahmatan lil alamiin dan moderat.

Salah satu kemoderatan Gulen adalah mengintegrasikan konsep pendidikan Islam kedalam dunia modern. Hal ini untuk menjadikan masyarakat paham terhadap pentingnya kombinasi keilmuan sains dan ilmu keagamaan sehingga pemahaman masyarakat tidak terbelenggu dengan materialisme, kapitalisme dan komunisme dan paham-paham lain yang menjadikan manusia mementingkan kebutuhan sesaat ${ }^{41}$. Oleh sebab itu, pendidikan adalah elemen utama untuk menjadikan manusia yang moderat, membentuk negera yang demokrasi dan memahami Islam secara utuh.

Rahmatan lil alamin bagi Gulen adalah cinta kasih kepada sesama, etika dan kebaikan moral adalah perilaku keseharian sehingga suasana harmonis tercipta. Cinta kasih dan harmonis tercipta ketika dasar-dasar tasawuf tertanam kuat dalam diri individu. Gulen menyadari cinta kasih dan harmonisme itu bisa tercipta ketika generasi muda diarahkan dalam pendidikan yang unggul dan belajar menghargai perbedaan dengan dialog dan toleransi. Sehingga sistem pendidikan yang

\footnotetext{
${ }^{37}$ M Arfan dan Abdul Wahid, Studi Islam, 515.

38 Gulen Fethullah, "Cinta Untuk Umat Manusia - Fethullah Gülen Situs Web,” diakses 30 Mei 2019, https://fgulen.com/id/karya-karya/1248-cinta-dan-toleransi/cinta-dan-kasih-sayang/33364-cinta-untuk-umat-manusia.

${ }^{39}$ Ahmad Kholil, "Cinta Sebagai Religious Peace Building (Perspektif Muhammad Fethullah Gülen)," Religi Jurnal Studi Agama-Agama 10, no. 2 (14 Agustus 2016): 149, https://doi.org/10.14421/rejusta.2014.1002-01.

${ }^{40}$ Khamami, "Paradigma Dakwah Islam Fethullah Gulen Di Abad Kontemporer," 377.

${ }^{41}$ Sulaiman, "Konsep Pendidikan Islam dalam Perspektif Muhammad Fethulah Gulen," 77.
} 
dibentuknya menjadikan lulusan yang memiliki jiwa pelopor perdamaian dunia, perdamaian yang universal tanpa memandang etnis, suku, budaya agama dan batas suatu negara lain ${ }^{42}$.

\section{Integrasi Model Pendidikan Islam dan Sains}

Menurut Gulen sains dan Islam harus berdampingan secara beriringan dan saling melengkapi satu sama lain ${ }^{43}$. Gulen mendorong para pengikutnya untuk memperkuat aspek esoteris Islam dengan mendalami tasawuf modern dan mendorong riset ilmiah untuk perkembangan dan kemajuan teknologi dami kesejahteraan umat manusia. Gulen melakukan integrasi Islam dan sains secara nyata, yaitu melakukan pendekatan Al-Qur`an dan Sunnah kepada sains. Begitu juga sebaliknya sains tidak terpisah dari sumber Islam yaitu Al-Qur`an dan Sunnah.

Gulen beranggapan bahwa kebenaran bukan berasal dari pikiran dan usaha manusia melainkan berdiri secara independen dan manusia harus mencarinya. Kebenaran itu komprehensif dan tidak bisa dipengaruhi oleh keterbatasan pengalaman individu manusia dan hanya menunggu untuk ditemukan. Menurut Gulen kebenaran itu terbagi menjadi dua macam yaitu kebenaran relatif dan kebenaran absolut/mutlak. Kebenaran relatif adalah kebenaran yang selalu berubah, tentatif dan bersifat sementara. Scientific truth/kebenaran ilmiah masuk pada bagian ini yang mana ilmu pengetahun selalu berubah-ubah. Kebenaran relatif dalam kenyataannya dapat berubah sewaktu-waktu karena kebergantungan pada data empiris dan intepretasi rasional pada data-data tersebut. Sedangkan kebenaran absolut adalah esensi dari segala eksistensi dan merupakan inti dari ilmu pengetahuan. Menurut Gulen ilmu pengetahuan modern masih belum mampu dan sangat lemah untuk mengetahui kebenaran di balik eksistensi ${ }^{44}$.

Kendati demikian, Gulen tidak mempertentangkan kedua kebenaran tersebut. Gulen sanggup mengakomodir keduanya menjadi harmonis. Bagaimana caranya? Gulen beranggapan bahwa alam semesta yang ada di dunia ini berwujud materi yang mana sebagai objek ilmu pengetahuan, semua itu pada dasarnya adalah perwujudan dari sifatsifat dan nama-nama Allah berwujud. Semua itu mengandung suatu kesucian yang tinggi sehingga Gulen menganjurkan untuk belajar dan mengetahui tentang kebesaran Tuhannya.

Penjelasan di atas menunjukkan ketegasan Gulen dalam bersikap bahwa kebenaran relatif pada ilmu pengetahuan tetap harus menjadi bagian penting dari kebenaran absolut. Kajian ilmiah/scientific truth dan kebenarannya yang relatif tetap mampu menjadi jembatan penghubung antara hamba dan sang pencipta sehingga ia benar-benar mampu mengetahui realitas kebenaran absolut melalui penampakan wujud Tuhan pada ilmu pengetahuan $^{45}$.

Gulen menambahkan tentang sains dan Islam harus bersanding secara harmonis dengan cara menjadikan Al-Qur`an sebagai pendekatan. Hal ini menepis para intelektual dan ilmuwan yang menganggap bahwa sains harus berpisah dengan agama. Ketika sains

\footnotetext{
42 Purnomo dan Umiarso, "Pengelolaan Dan Sistem Pendidikan Islam Berwawasan Rahmatan Lil'alamin,” 237.

${ }^{43}$ Khamami, "Dialog antariman dalam Perspektif Fethullah Gülen," 14.

${ }^{44}$ Billa, "Pemaknaan Teologis M. Fethullah Gülen tentang Relasi Agama dan Sains," 304.

${ }^{45}$ Billa, 306.
} 
harus berpisah dengan agama dan Al-Qur`an maka kekeringan akan muncul dan menjadikan pribadi seorang semakin jauh dengan eksistensi dan esensi kehidupan. AlQur`an sebagai pendekatan filosofis bagi pengetahuan menurut Gulen adalah untuk menginspirasi setiap individu dengan cinta kebenaran, cinta yang timbul dari hati kerena kebenaran absolut sehingga menjadikan manusia lebih bersifat manusiawi, toleran dan kasih sayang.

Melalui pendidikan Gulen menyebarkan paham integrasi kajian Islam dan sains agar membantu mengentaskan tugas ilmiah modern dari lubang mematikan yang telah terinfeksi sifat fanatisme ideologis dan materialistis serta mengajak para cendikia untuk mengamalkan nilai-nilai kemanusiaan dengan perdamaian. Pendekatan Al-Qur`an menekankan pada belajar ilmiah pada nilai-nilai luhur kemanusiaan. Sehingga dalam melakukan kajian ilmiah dan pendidikan harus dapat mewujudkan tujuan mendasar dalam Qur`an yaitu: 1) membuktikan kebesaran dan keberadaan Tuhan Yang Maha Esa, 2) membuktikan kebenaran kenabian 3) untuk membuktikan kebenaran hari kebangkitan dan 4) berkosentrasi pada keadilan dan ibadah kepada Allah $^{46}$.

Gulen melaksanakan seluruh pemikiran dan konsepnya pada pelayanan kemanusiaan (hizmet) pada aspek pendidikan. Pendidikan adalah cara tepat untuk menyebarkan Islam dan sains hidup harmonis, agama yang cinta kasih dan rahmatan lil alamin. Hal ini tentunya tidak mudah diterapkan oleh Gulen. Ia merekrut guru-guru lulusan terbaik di Turki untuk dijadikan model dan uswah bagi peserta didik yang lainnya. Gulen merekrut guru dengan cara selektif dan diseleksi secara ketat dan bertanggung$\mathrm{jawab}^{47}$. Menurut Gulen, guru merupakan representasi ilmu pengetahuan, akhlak, keimanan dan seni. Pendidik adalah agen perubahan yang mana tidak sekedar mentransfer ilmu, tetapi lebih dari itu, yaitu dengan cara mendidik, memberikan nilai, membentuk karakter dan menjadi teladan bagi setiap murid-muridnya.

Bagi Gulen guru merupakan aspek penting dalam membentuk sistem pendidikan yang unggul. Bahkan peran guru tidak bisa digantikan oleh teknologi apapun dalam proses pendidikan ${ }^{48}$. Guru merupakan tugas mulia yang sama dengan Nabi SAW. Guru memberikan tauladan kepada setiap muridnya, membentuk sikap spiritual yang baik, cinta kasih dan mencintai perdamaian. Hal ini dijelaskan dalam prinsip-prinsip guru yang baik dalam mendidik oleh Gulen sebagai berikut:

1. Pendidik haruslah mengajar dengan cinta dan memberikan ilmunya dengan metode yang terbaik.

2. Pendidik harus mampu memahami psikologis peserta didik, yakni pendidik harus mampu menjadi fasilitator agar peserta didik mampu memahami ilmu yang diberikan.

3. Jangan melanjutkan materi apabila materi sebelumnya belum dipahami secara penuh oleh peserta didik.

\footnotetext{
${ }^{46}$ Billa, 312.

${ }^{47}$ Purnomo dan Umiarso, "Pengelolaan Dan Sistem Pendidikan Islam Berwawasan Rahmatan Lil'alamin," 235.

${ }^{48}$ Sulaiman, "Konsep Pendidikan Islam dalam Perspektif Muhammad Fethulah Gulen," 73.
} 
4. Jika peserta didik mempunyai kelemahan dan kesalahan maka pendidik tidak boleh mengumbar hal tersebut. Oleh sebab itulah Gulen merekomendasikan pendidikan dengan humanistik dan toleransi agar semua mencintai satu sama lainya.

5. Pendidik harus mampu menjadi tempat konseling peserta didik, mampu mendengarkan keluhan dan kelemahan peserta didik dan memberika dukungan penuh untuk mewujudkan cita-citanya.

\section{Kesimpulan}

Gulen mempunyai pemikiran pendidikan holistik antara aspek esoteris dan eksoteris serta sekaligus menerapkannya dalam lembaga pendidikan yang dibentuknya. Gulen tidak pernah memisahkan antara keilmuan agama dan sains. Keduanya merupakan aspek yang saling mendukung satu sama lain agar seorang tidak terlalu fanatik ketika hanya memahami ilmu keislaman saja dan agar tidak materialistis ketika hanya memahami ilmu sains saja. Gulen menerapkan cinta Al-Qur`an sejak kecil agar peserta didik mampu memahami Islam dan sains secara utuh dan komprehensif. Gulen melaksanakan seluruh pemikiran dan konsep pendidikannya dengan hizmet yaitu melayani manusia agar terjalin hubungan harmonis.

Tujuan utama Gulen membentuk lembaga pendidikan adalah untuk menjadikan lulusan mengerti akan cinta yang sesungguhnya, cinta kepada setiap makhluk, cinta kepada sesama dan cinta kepada Tuhan yang maha Esa. Dasar untuk melaksanakan hizmet adalah cinta, dengan cinta harmonisasi dalam pendidikan akan terjalin. Radikalisme dan kekerasan akan terurai ketika cinta memenuhi diri seorang sehingga cinta merupakan pokok seorang dalam melakukan tugasnya. Termasuk seorang pendidik yang harus mencintai peserta didiknya, mencintai pekerjaannya dan mencintai ilmu yang dimilikinya.

\section{Ucapan Terima Kasih}

Ucapan terima kasih kepada: Dr Khudori Soleh, Ag. sebagai dosen pengampu mata kuliah Filsafat Ilmu Islam Kontemporer.

\section{Daftar Pustaka}

Afsaruddin, Asma. "The philosophy of Islamic education: Classical views and M. Fethullah Gulen's perspectives." dalam laman http://fethullahgulenconference. org/houston/read. php, 2005.

Alba, H. Cecep. Tasawuf dan Tarekat: Dimensi Esoteris Ajaran Islam. Cet. 1. Bandung: Anggota Ikapi, 2012.

Amin, Hulaimi Al. "Pandangan Fethullah Gulen Tentang Toleransi Beragama." AlMajaalis 4, no. 1 (20 November 2016): 149-81.

Baharuddin. Paradigma Psikologi Islami, Studi tentang Elemen Psikologi dari Al-Quran. 2 ed. Yogyakarta: Pustaka Pelajar, 2007. 
Bilici, Mucahit. "The Fethullah Gulen Movement and Its Politics of Representation in Turkey*." The Muslim World 96, no. 1 (Januari 2006): 1-20. https://doi.org/10.1111/j.1478-1913.2006.00115.x.

Billa, Mutamakkin. "Pemaknaan Teologis M. Fethullah Gülen tentang Relasi Agama dan Sains." Teosofi: Jurnal Tasawuf Dan Pemikiran Islam 1, no. 2 (1 Desember 2011): 290-316. https://doi.org/10.15642/teosofi.2011.1.2.290-316.

Çelik, Gürkan. The Gülen movement: building social cohesion through dialogue and education. Delft: Eburon, 2010.

Chittick, William C. Jalan Cinta Sang Sufi, Ajaran-Ajaran Spiritual Jalaluddin Rumi. Diterjemahkan oleh Ismail M Sadat dan Nidjam Achmad. 2 ed. Yogyakarta: Qalam, 2000.

Ebaugh, Helen Rose Fuchs. The Gülen movement: a sociological analysis of a civic movement rooted in moderate Islam. Dordrecht [the Netherlands] ; London ; New York: Springer, 2010.

Fethullah, Gulen. "Biografi Singkat Fethullah Gülen - Fethullah Gülen Situs Web." Diakses 30 Mei 2019. https://fgulen.com/id/profil/biografi-fethullahgulen/34168-biografi-singkat-fethullah-gulen.

. "Cinta Untuk Umat Manusia - Fethullah Gülen Situs Web." Diakses 30 Mei 2019. https://gulen.com/id/karya-karya/1248-cinta-dan-toleransi/cinta-dankasih-sayang/33364-cinta-untuk-umat-manusia.

"Educational services are spreading throughout the world - Fethullah Gülen's Official Web Site." Diakses 28 Mei 2019. https://fgulen.com/en/fethullahgulens-works/toward-a-global-civilization-of-love-and-

tolerance/education/25270-educational-services-are-spreading-throughout-theworld.

. "Pendidikan Dasar dan Kepribadian M. Fethullah Gülen - Fethullah Gülen Situs Web." Diakses 30 Mei 2019. https://gulen.com/id/profil/biografi-fethullahgulen/33351-pendidikan-dasar-dan-kepribadian-m-fethullah-gulen.

. "Siapakah Fethullah Gülen? - Fethullah Gülen Situs Web." Diakses 30 Mei 2019. https://fgulen.com/id/profil/biografi-fethullah-gulen/35531-siapakahfethullah-gulen.

Gülen, Fethullah. Pearls of wisdom. Fairfax, Va: The Fountain, 2000.

Towards the lost paradise. 2nd ed. Konak, İzmir: Kaynak, 1998.

Haderi, Anang. “Takdir Dan Kebebasan Menurut Fethullah Gülen.” Jurnal Theologia25, no. 2 (2014): 49-80. https://doi.org/10.21580/teo.2014.25.2.381.

Huda, Sokhi. "Pemikiran Dan Praksis Dakwah Sufistik M. Fethullah Gülen." ISLAMICA: Jurnal Studi Keislaman 11, no. 2 (13 Maret 2017): 311-38. https://doi.org/10.15642/islamica.2017.11.2.311-338.

Tribakti: Jurnal Pemikiran Keislaman

Volume 30, Nomor 2, Juli 2019 
Imam, Hairul. "Perspektif M. Fethullah Gulen tentang Golden Generation dan Relevansinya dengan Pendidikan Islam di Indonesia." Marâji: Jurnal Ilmu Keislaman 2, no. 2 (1 Maret 2016): 248-78.

Keskin, Tugrul. "A Comparative Analysis of Islamist Movements in the Neoliberalization Process: Jamaâ at-e- Islami in Pakistan and the Fethullah Gulen Movement in Turkey â Reactions to Capitalism, Modernity and Secularism," $\quad 9 \quad$ September 2009. https://vtechworks.lib.vt.edu/handle/10919/29681.

Khamami, Ahmad Rizqon. "Dialog antariman dalam Perspektif Fethullah Gülen." Religio: Jurnal Studi Agama-Agama 2, no. 1 (2012).

Khamami, Akhmad Rizqon. "Paradigma Dakwah Islam Fethullah Gulen Di Abad Kontemporer." Islamica: Jurnal Studi Keislaman 12, no. 2 (29 November 2018): 358-83. https://doi.org/10.15642/islamica.2018.12.2.358-383.

Kholil, Ahmad. "Cinta Sebagai Religious Peace Building (Perspektif Muhammad Fethullah Gülen)." Religi Jurnal Studi Agama-Agama 10, no. 2 (14 Agustus 2016): 141-57. https://doi.org/10.14421/rejusta.2014.1002-01.

M Arfan, Mua'mmar, dan Hasan Abdul Wahid. Studi Islam Perspektif Insider dan Outsider. 2 ed. Yogyakarta: IRCiSoD Anggota Ikapi, 2013.

Nelson, Charles. "Fethullah Gülen: A Vision of Transcendent Education,” t.t., 13.

Park, Bill. "The Fethullah Gülen Movement as A,” t.t., 14.

Purnomo, Hadi, dan Umiarso Umiarso. "Pengelolaan Dan Sistem Pendidikan Islam Berwawasan Rahmatan Lil'alamin: Kajian Atas Gerakan Pendidikan Fethullah Gulen Movement." Cendekia: Jurnal Kependidikan Dan Kemasyarakatan 16, no. 2 (22 November 2018): 223-44. https://doi.org/10.21154/cendekia.v16i2.1288.

Putra, D. I. Ansusa. "Epistemologi Tafsir Sufi Perspektif Esoterik-Fenomenologi." Ulul Albab Jurnal Studi Islam 19, no. 2 (28 Desember 2018): 185-208. https://doi.org/10.18860/ua.v19i2.5019.

Roman, Muzalevsky. "Fethullah Gulen's Movement in Central Asia: A Blessing or a Curse?" Diakses $28 \quad$ Mei 2019. http://www.cacianalyst.org/publications/analytical-articles/item/11895analytical-articles-caci-analyst-2009-9-1-art-11895.html.

Sulaiman, Mubaidi. "Konsep Pendidikan Islam dalam Perspektif Muhammad Fethulah Gulen.” Didaktika Religia 4, no. 2 (2016): 61-86.

Yucel, Salih. "Fethullah Gulen: Spiritual Leader in a Global Islamic Context," 2010. https://dspace2.creighton.edu/xmlui/handle/10504/64593. 